\title{
New Mobile Website and JABFM Editorial Board Member Elected to the Institute of Medicine
}

\author{
Phillip Lupo, Jr., MLIS, Anne Victoria Neale, PhD, MPH, and
} Marjorie A. Bowman, MD, MPA

\section{JABFM's New Mobile Website}

The $7 A B F M$ mobile website is more "user friendly" for small phone screens. It is now live and ready for use. Users are redirected to the mobile website after simply typing "jabfm.org" into their web browser on their Smartphone. The home page has been streamlined for easier searching capabilities (Figure 1), and all $7 A B F M$

Figure 1.JABFM mobile website home page.

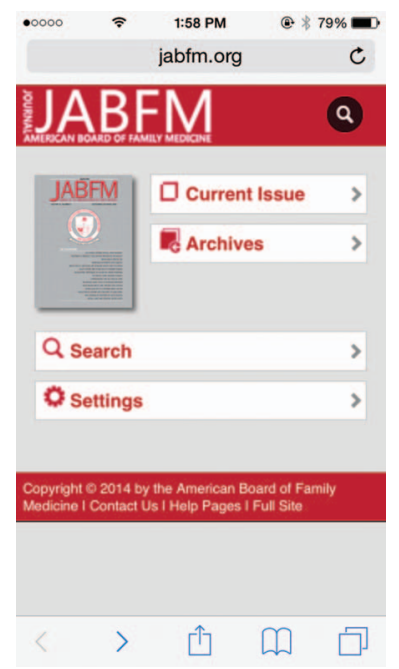

articles have been reformatted and resized for simpler reading (Figure 2). We hope you find this to be a useful tool at your office or wherever you find yourself when needing to access the $7 A B F M$ website.

Conflict of interest: The authors are editors and staff of the 7ABFM.
Figure 2.JABFM mobile website article.

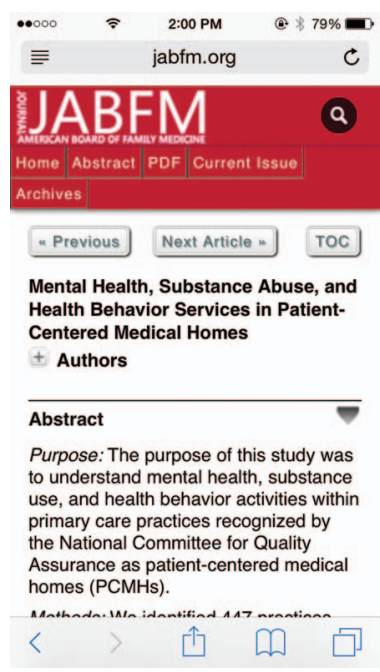

\section{JABFM Editorial Board Member Elected to the Institute of Medicine}

We are proud to announce that $7 A B F M$ editorial board member, Jennifer Devoe, MD, DPhil, was

Jennifer Devoe, MD, DPhil.

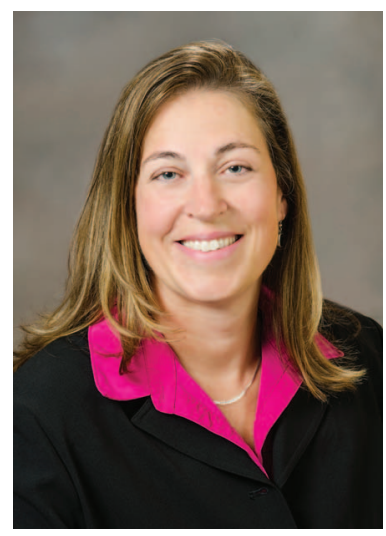


recently elected to the Institute of Medicine (IOM), which is considered to be one of the highest honors in medicine. Dr. Devoe, an associate professor of family medicine at Oregon Health \& Science University, was elected during the IOM's 44th annual meeting in Washington, DC, this past October. For more information, please see the announcement on Oregon Health \& Science University's website at: http://www.ohsu.edu/xd/education/ schools/school-of-medicine/departments/clinicaldepartments/family-medicine/research-scholarship/ devoe_iom.cfm.

Other editorial board members elected to the IOM include Alfred O. Berg, MD, MPH; Larry Green, MD; Richard Clover, MD; and Larry Culpepper, MD, MPH. 